\title{
Retinal degeneration in mice and humans with neuronal ceroid lipofuscinosis type 8
}

\author{
Elyse M. Salpeter ${ }^{1}$, Brian C. Leonard ${ }^{1}$, Antonio J. Lopez ${ }^{2}$, Christopher J. Murphy ${ }^{1,2}$, Sara Thomasy ${ }^{1,2}$, \\ Denise M. Imai ${ }^{3}$, Kristin Grimsrud ${ }^{4,5}$, K. C. Kent Lloyd ${ }^{4,6}$, Jiong Yan $^{7}$, Rossana Sanchez Russo ${ }^{8}$, \\ Suma P. Shankar ${ }^{9}$, Ala Moshiri ${ }^{2} \wedge$
}

${ }^{1}$ William R. Pritchard Veterinary Medical Teaching Hospital, School of Veterinary Medicine, University of California, Davis, Davis, California, USA; ${ }^{2}$ Department of Ophthalmology \& Vision Science, School of Medicine, University of California, Davis, Sacramento, California, USA; ${ }^{3}$ Comparative Pathology Laboratory, School of Veterinary Medicine, UC Davis, Davis, California, USA; ${ }^{4}$ Mouse Biology Program, University of California, Davis, Davis, California, USA; ${ }^{5}$ Department of Pathology and Laboratory Medicine, School of Medicine, University of California, Davis, Sacramento, California, USA; ${ }^{6}$ Department of Surgery, School of Medicine, University of California, Davis, Sacramento, California, USA; ${ }^{7}$ Department of Ophthalmology, Emory University, Atlanta, Georgia, USA; ${ }^{8}$ Department of Human Genetics, Emory University, Atlanta, Georgia, USA; ${ }^{9}$ Department of Pediatrics \& Department of Ophthalmology \& Vision Science, School of Medicine, University of California, Davis, Sacramento, California, USA

Contributions: (I) Conception and design: EM Salpeter, A Moshiri, SP Shankar; (II) Administrative support: BC Leonard, CJ Murphy, S Thomasy, DM Imai; (III) Provision of study materials or patients: K Grimsrud, KCK Lloyd, J Yan, R Sanchez Russo, SP Shankar; (IV) Collection and assembly of data: EM Salpeter, AJ Lopez; (V) Data analysis and interpretation: EM Salpeter, A Moshiri; (VI) Manuscript writing: All authors/Both authors; (VII) Final approval of manuscript: All authors/Both authors.

Correspondence to: Ala Moshiri, MD, PhD. Department of Ophthalmology and Vision Science, School of Medicine, University of California, Davis Eye Center, 4860 Y. Street, Suite 2400, Sacramento, CA 95817, USA. Email: amoshiri@ucdavis.edu.

Background: Ceroid lipofuscinosis type 8 belongs to a heterogenous group of vision and life-threatening neurodegenerative diseases, neuronal ceroid lipofuscinosis (NCL). Effective therapy is limited to a single drug for treatment of ceroid lipofuscinosis type 2, necessitating animal disease models to facilitate further therapeutic development. Murine models are advantageous for therapeutic development due to easy genetic manipulation and rapid breeding, however appropriate genetic models need to be identified and characterized before being used for therapy testing. To date, murine models of ocular disease associated with ceroid lipofuscinosis type 8 have only been characterized in motor neuron degeneration mice.

Methods: $C \ln 8^{-/-}$mice were produced by CRISPR/Cas9 genome editing through the International Mouse Phenotyping Consortium. Ophthalmic examination, optical coherence tomography, electroretinography, and ocular histology was performed on $C \ln 8^{-/-}$mice and controls at 16 weeks of age. Quantification of all retinal layers, retinal pigmented epithelium, and the choriocapillaris was performed using images acquired with ocular coherence tomography and planimetry of histologic sections. Necropsy was performed to investigate concurrent systemic abnormalities. Clinical correlation with human patients with CLN8-associated retinopathy is provided.

Results: Retinal degeneration characterized by retinal pigment epithelium mottling, scattered drusen, and retinal vascular attenuation was noted in all $\operatorname{Cln}^{-/-}$mice. Loss of inner and outer photoreceptor segment demarcation was noted on optical coherence tomography, with significant thinning of the whole retina $(\mathrm{P}=1 \mathrm{e}-9)$, outer nuclear layer $(\mathrm{P}=1 \mathrm{e}-9)$, and combined photoreceptor segments $(\mathrm{P}=1 \mathrm{e}-9)$. A global reduction in scotopic and photopic electroretinographic waveforms was noted in all $\operatorname{Cln} 8^{-/-}$mice. Slight thickening of the inner plexiform layer $(\mathrm{P}=0.02)$ and inner nuclear layer $(\mathrm{P}=0.004)$, with significant thinning of the whole retina $(\mathrm{P}=0.03)$, outer nuclear layer $(\mathrm{P}=0.01)$, and outer photoreceptor segments $(\mathrm{P}=0.001)$ was appreciated on histologic sections. Scattered lipid vacuoles were noted in splenic red pulp of all $C \ln 8^{-/-}$mice, though no

\footnotetext{
$\wedge$ ORCID: 0000-0002-4277-8094.
} 
gross systemic abnormalities were detected on necropsy. Retinal findings are consistent with those seen in patients with ceroid lipofuscinosis type 8 .

Conclusions: This study provides detailed clinical characterization of retinopathy in adult $C \ln 8^{-/}$mice. Findings suggest that $C \ln 8^{-/-}$mice may provide a useful murine model for development of novel therapeutics needed for treating ocular disease in patients with ceroid lipofuscinosis type 8 .

Keywords: Neuronal ceroid lipofuscinosis; retinal degeneration; murine model

Submitted Jun 16, 2020. Accepted for publication Mar 19, 2021.

doi: 10.21037/atm-20-4739

View this article at: https://dx.doi.org/10.21037/atm-20-4739

\section{Introduction}

The International Mouse Phenotyping Consortium (IMPC) is a cooperative association that employs high throughput mouse mutagenesis and comprehensive phenotyping with the goal of creating the first functional encyclopedia of the mammalian genome $(1,2)$. Additionally, CRISPR/Cas9 genome editing through the IMPC facilitates production and identification of murine models for human disease, such as the recent creation of a bio-engineered neuronal ceroid lipofuscinosis type 8 (CLN8) murine model with ocular manifestation. Neuronal ceroid lipofuscinosis (NCL) is a heterogenous group of progressive, life-threatening, neurodegenerative disorders characterized by lysosomal accumulation in multiple tissues of the central nervous system (3). Progressive epilepsy with mental retardation was recognized as a NCL subtype (CLN8) $(4,5)$. CLN8 is an endoplasmic reticulum (ER) associated membrane protein required for transfer of lysosomal enzymes from the ER to the Golgi complex; deficiency leads to depletion of soluble enzymes in the lysosome, thus impairing lysosome biogenesis and lysosomal enzyme transport (6). Metabolic radiolabeling has highlighted delayed lysosomal enzyme maturation with CLN8 deficiency, which was rescued by CLN8 re-expression in CLN8-deficient cells obtained by CRISPR/Cas9 genome editing (6).

Ocular symptoms such as retinal degeneration can be the first sign of NCL disease and facilitate an early diagnosis (7). Ocular manifestations of NCL are most commonly noted with CLN3 $(8,9)$, though retinopathy and visual deficits associated with CLN8 have also been reported (10).

All NCL subtypes are unique inherited metabolic disorders, limiting specific pharmacologic treatments to single genetic forms, or groups of disorders that share an underlying metabolic pathway defect (11). Development of improved therapeutics is needed for the majority of NCL subtypes, with effective pharmacologic therapy limited to a single clinically approved drug, Cerliponase alfa (Brineura $^{\mathrm{TM}}$, BioMarin Pharmaceutical Inc., Novato, CA, USA), for treatment of CLN2 $(12,13)$.

Murine models of human disease are an important component in therapeutic development due to the relative ease of genetic manipulation and short generational interval. These models contribute to therapeutic development through facilitating investigation of disease pathophysiology, aiding in identification of therapeutic targets, and facilitating initial assessment of efficacy of therapeutic approaches. To date, murine models have been identified for CLN1 (14-17), CLN2 (18), CLN3 (17,19-28), CLN5 (29), CLN6 (30), CLN8 (31-35), and CLN10 (36,37). Reports of retinopathy characterization in murine models of NCL predominantly describe findings in CLN3 (19,28), CNL5 (38), CNL6 (39), and CLN8 (32-35), though the available descriptions of ocular disease associated with CLN8 are limited to homozygous motor neuron degeneration (mnd) murine models. Neural degeneration in the mnd model results from spontaneous defect in the murine orthologue of CLN8 and exhibits pathology similar to human NCLs $(32,40)$.

\section{Spontaneous mutations in CLN8 have also been identified in canines (41-43)}

To the authors' knowledge, phenotypic characterization of retinopathy in CLN8 murine models is limited to a report of indirect ophthalmoscopic and electroretinographic findings, and limited reports of histopathological changes in $m n d$ mice $(33-35,40)$. The aim of this study was therefore to define the clinical, electrophysiologic, and anatomic retinal changes in a novel mouse model with targeted deletion of $C \ln 8$. Complete characterization will better inform the use of $\operatorname{Cn} 8^{-/-}$mice as animal models for development 
of improved therapeutics and management of CLN8 retinopathy in humans.

We present the following article in accordance with the ARRIVE reporting checklist (available at https://dx.doi. org/10.21037/atm-20-4739).

\section{Methods}

\section{Study design}

The study included one experimental group with $\operatorname{Cln} 8^{-/-}$ mice, and one control group with C57BL/6N wildtype. All mice underwent an ophthalmic examination, ocular imaging, electroretinography, and necropsy at 16 weeks of age. Investigators were blinded to genetic profiles when performing ophthalmic examinations, analysis of ocular images, analysis of electroretinograms, and necropsies. This report also reviews two cases of CLN8 in humans, to highlight similarities with the murine model in this study.

\section{Animals}

Experiments were performed under a project license (No. IACUC \# 21824) granted by the Institutional Animal Care and Use Committee at UC Davis, in compliance with the National Institutes of Health (NIH) Guide for the Care and Use of Laboratory Animals and the guidelines of the Association for Research in Vision and Ophthalmology Statement for the Use of Animals in Ophthalmic and Vision Research.

All mice were housed and cared for in accordance with the recommendations provided in the Guide for the Care and Use of Laboratory Animals Eighth Edition. Mice were cohoused by gender groups of 4-5 animals per cage in individually ventilated cages (optimice IVC, Animal Care Systems, Centenniel, CO) on a 12:12 hour (06:00-18:00) light cycle. Temperature ranges in the room are maintained between $68-79^{\circ} \mathrm{F}$ and mice are maintained on standard laboratory rodent chow (Rodent chow, Envigo 2918).

To study the in vivo function of $\mathrm{Cln} 8$, gene-specific knockout mice $\left(\mathrm{Cln}^{-/-}\right)$were generated using CRISPR/ Cas9 genome editing. Briefly, one-cell state C57BL/6N zygotes were harvested from super ovulated female mice and electroporated using standard protocols with a ribonucleoprotein (RNP) consisting of Cas9 protein and two synthetic guide RNAs (gRNA) internal to the coding region of exon 1 (CGGCCAAAGAGAAGGTCTTC \& GGCGTCCAGAGCACAACTGC). The deletion causes a frameshifted transcript of all known isoforms, effectively resulting in a null allele by nonsense protein/ early termination and potential for nonsense mediated decay (NMD) of the transcript. Embryos were surgically transferred into the oviducts of pseudopregnant CD1 female mice. After gestation and littering, pre-weaned mouse pups were sampled and genetically tested by endpoint PCR and sequencing to definitively identify founder mice harboring the desired internal frameshift deletion. Subsequent germline transmission mice (N1) were further sequenced to confirm the desired deletion which consists of a $53 \mathrm{bp}$ deletion (GGTCTTCTGGAACCTGGCGG CGACGCGTGCTGTCTTCGGCGTCCAGAGCAC AA) of the $183^{\text {rd }}$ to $235^{\text {th }}$ coding nucleotides which creates an early stop signal within exon 1, preceded by 28 amino acid nonsensical sequence. After weaning, sexually mature mice with confirmed germline transmission of the desired deletion allele were backcrossed two generations before intercrossing heterozygous mice to generate homozygous knockouts. Sex (male and female) and Mendelian (zygosity) ratios were normal as expected. In total, five heterozygous breeding trios produced a total of 133 pups with normal male and female distribution. The zygosity distribution was reported to be $45.9 \%$ heterozygous, $29.3 \%$ homozygous and $24.8 \%$ wildtype. Overall, breeding and animal health were within normal expectations for this mouse line and no observable abnormalities were observed during production or while maintaining these mice. For this study, $3 \mathrm{Cln}^{-/-}$ mice were available for analysis, and 2 wildtype, and 1 $\mathrm{Cln} 8^{+/-}$mouse were chosen as age-matched controls.

\section{Ophthalmic examination}

Complete ophthalmic examinations were performed on both eyes of $3 \mathrm{Cln}^{-/-}, 1 \mathrm{Cln} 8^{8^{+-}}$, and $\mathrm{C} 57 \mathrm{BL} / 6 \mathrm{~N}$ wildtype mice at 16 weeks of age. A standardized operating protocol for evaluation of ocular and adnexal structures was followed at the UCDavis study site (https://www.mousephenotype. org/impress/protocol/267/7) and were carried out by experienced technical support staff trained to identify and differentiate background lesions common in the C57BL/6N strain (44). Examiners were overseen by lead site scientists who subsequently reviewed all phenotypes. Pupillary light reflexes were evaluated, the eyelids, third eyelid, conjunctiva, sclera, cornea, iris, and anterior chamber were examined using broad beam illumination at the highest intensity setting (Kowa SL-15, Kowa, Tokyo, Japan, or equivalent) with magnification set at $16 \mathrm{X}$. The irides of all 
mice were then pharmacologically dilated with a solution of 1:7 10\% phenylephrine HCl (Akorn Inc., Lake Forest, IL, USA, or equivalent): $1 \%$ tropicamide (Bausch \& Lomb Inc., Tampa, FL, USA, or equivalent). A $0.1 \mathrm{~mm}$ slit beam at the highest intensity setting was used to evaluate the anterior segment (cornea, anterior chamber, and lens), followed by evaluation of the retrolental region of the vitreous.

Fundus examinations were performed via indirect ophthalmoscopy using a 60 Diopter double aspheric handheld lens (Volk Optical Inc, Mentor, OH, USA or equivalent) and a portable indirect headset (Keeler AllPupil II LED Vantage Plus Wireless Headset, Keeler Instruments Inc., Broomall, PA, USA).

\section{Ocular imaging}

A cocktail of ketamine/medetomidine $(100 / 0.3 \mathrm{mg} / \mathrm{kg})$ was administered intraperitoneally to induce anesthesia in all mice undergoing ocular imaging. Fundus photographs were acquired with the Micron III (Phoenix Research Laboratories, Pleasanton, CA, USA).

OCT imaging was performed with an Envisu R2200 SDOCT (spectral-domain OCT; Bioptigen-Leica, Wetzlar, Germany), after dilatation with both tropicamide $1 \%$ and phenylephrine $2.5 \%$. Thickness of the total retina, nerve fiber layer, retinal ganglion cell layer, inner plexiform layer, inner nuclear layer, outer plexiform layer, outer nuclear layer, combined inner and outer photoreceptor segments, retinal pigmented epithelium, and choriocapillaris were manually measured at a distance of $\sim 0.2 \mathrm{~mm}$ from each side of the optic nerve using calipers in ImageJ software according to established guidelines (45). Measurements from both sides of the optic nerve head and between left and right eyes were averaged for each animal.

\section{Electroretinography}

Following a 12-hour dark adaptation period, the mice received a cocktail of ketamine/medetomidine $(100 / 0.3 \mathrm{mg} / \mathrm{kg})$ intraperitoneally to induce anesthesia. A single drop of both tropicamide $1 \%$ and phenylephrine $2.5 \%$ was used for dilation, and the ocular surface was lubricated with methylcellulose-containing artificial tears. Standard full field scotopic and photopic electroretinography (ERG) was performed on both eyes with LKC Big Shot with a Ganzfeld dome (LKC Technologies Inc., Gaithersburg, MD, USA). For quantitative comparisons, measurements were averaged between the two eyes of each animal.

\section{Histology}

Eyes were removed and immediately fixed in $2.5 \%$ glutaraldehyde and $2 \%$ paraformaldehyde in $0.1 \mathrm{M}$ sodium phosphate buffer. Parasagittal sections of eyes were processed routinely for histopathology, embedded in paraffin, sectioned at $5 \mu \mathrm{m}$, and stained with hematoxylineosin (H\&E). Retinal layer measurements were taken of total retina, nerve fiber layer, retinal ganglion cell layer, inner plexiform layer, inner nuclear layer, outer plexiform layer, outer nuclear layer, inner photoreceptor segment, outer photoreceptor segment, retinal pigmented epithelium, and choriocapillaris on imaged $\mathrm{H} \& \mathrm{E}$ sections as described above for OCT images.

\section{Immunobistochemistry}

Sections were deparaffinized using three changes of xylenes for 5 minutes each. The tissue sections were then stepwise hydrated by submersion in 100\% ethanol (twice), $95 \%$ ethanol, $75 \%$ ethanol, and distilled water- 5 minutes per step. Heat-induced epitope retrieval was then performed with $1 \mathrm{mM}$ EDTA, $\mathrm{pH}$ 8.0. The tissue sections were then blocked for 30min in blocking solution (4\% BSA and $0.5 \%$ Triton X-100 in PBS) at ambient temperature. Primary antibodies (rabbit anti-cleaved PARP-94885S Cell Signaling @ 1:100, mouse anti-rhodopsin-MABN15 Sigma-Aldrich @ 1:1,000) were then incubated overnight at 4C. The slides were washed three times in with PBS for five minutes each. Alexa Fluor conjugated secondary antibodies (A32723 and A32740- ThermoFisher Scientific) were incubated for an hour followed by a 5 -minute incubation in DAPI $(1 \mu \mathrm{g} / \mathrm{mL})$. The tissue sections were washed with PBS three times for five minutes each. Finally, the slides were cover slipped with FluorSave Reagent (Millipore, 345789).

\section{TUNEL}

Detection of apoptotic cells was conducted using ApopTag ${ }^{\circledR}$ Fluorescein In Situ Apoptosis Detection Kit (S7110, SigmaAldrich). Sections were deparaffinized and hydrated like the immunohistochemistry method and then treated with proteinase $\mathrm{K}(20 \mu \mathrm{g} / \mathrm{mL})$ at ambient temperature. The tissue sections were then washed twice with PBS for 2 minutes each. The tissue sections were equilibrated and the TdT 

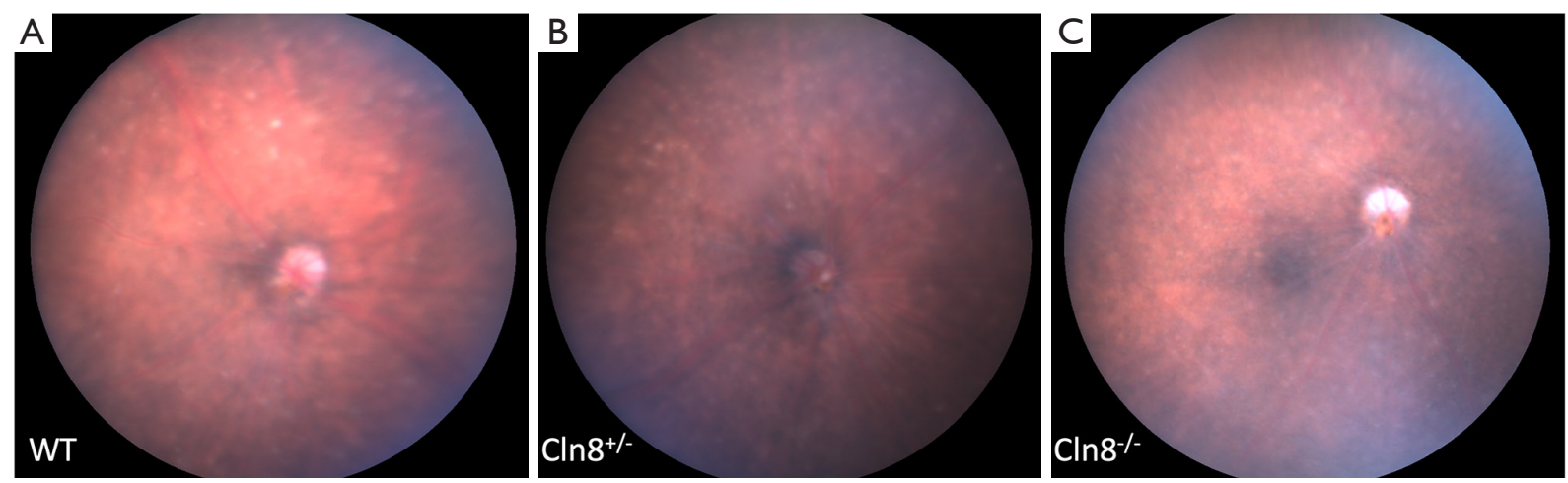

Figure 1 Fundus images of wildtype, $C \ln 8^{+/-}$, and $C \ln 8^{-/-}$mice. (A) Fundus of wildtype C57BL/6N $r d 8$ mouse and (B) $C \ln 8^{+/-}$mouse with mild retinal dysplasia and normal retinal vasculature. (C) Fundus of $C \ln 8^{-/-}$mouse with optic nerve pallor, retinal vascular attenuation, and diffuse retinal pigment epithelium mottling.

enzyme was applied for an hour at $37^{\circ} \mathrm{C}$. The reaction was then stopped with the stop buffer and the sections were washed three times in PBS for 1 minute each. The antidigoxigenin conjugate was then applied for 30 minutes at ambient temperature followed by a 5 -minute incubation with DAPI $(1 \mu \mathrm{g} / \mathrm{mL})$. The sections were washed 4 time in PBS for 2 minutes each. Finally, the slides were cover slipped with FluorSave Reagent (Millipore, 345789). TdT enzyme, equilibration buffer, stop buffer and anti-digoxigenin conjugate were provided with the kit.

\section{Necropsy}

Routine necropsy was performed at the UC Davis IMPC location on all $\operatorname{Cln} 8^{-/-}, \operatorname{Cn} 8^{+/-}$, and wildtype mice immediately following $\mathrm{CO}_{2}$ euthanasia at 16 weeks of age. Samples were taken from all major internal organs, processed routinely for histopathology, and stained with H\&E.

\section{Clinical cases}

The study was conducted in accordance with the Declaration of Helsinki (as revised in 2013). The study was approved by the Institutional Review Board of Emory University (No. MODCR001-IRB00024817). Both patients provided written permission to contribute clinical data to this research article.

Descriptions of the ophthalmic findings from routine ophthalmologic examination are provided for the sibling pair of CLN8 patients. Retinal imaging was acquired, including ultrawide field color fundus imaging (Optos, United Kingdom) and spectral domain OCT (Zeiss Cirrus instrument, Germany).

\section{Statistical analysis}

For comparisons of retinal layer thicknesses between $\operatorname{Cln} 8^{-/-}$ and control ( $\mathrm{Cln} 8^{+/-}$and/or wildtype) mice on OCT images and H\&E sections, a 2-tailed Student's $t$-test was performed. A P value $<0.05$ was considered statistically significant.

\section{Results}

\section{Ophthalmic examination}

On ophthalmic examination of the anterior segment, standard background lesions previously described for C57BL/6N $r d 8$ mice were noted in both eyes of all $\operatorname{Cln} 8^{-/}$, $\mathrm{Cln} 8^{+/}$, and wildtype mice (44). These lesions included: mild mucoid ocular discharge, subtle incipient nuclear cataracts, and small vitreous accumulations of crystalline appearing material and pigment.

On fundus examination, retinal pathology in the eyes of wildtype (Figure $1 A$ ) and $C \ln 8^{+/-}$(Figure $1 B$ ) mice was limited to mild to moderate retinal dysplasia, as previously described amongst background lesions for the C57BL/6N strain (44). By comparison, diffuse retinal degeneration was noted in all homozygous knockout eyes, characterized by retinal pigment epithelium mottling in all retinal quadrants, and retinal vascular attenuation (Figure 1C).

\section{Optical coherence tomography (OCT)}

Retinal measurements and their associated $\mathrm{P}$ values 
Table 1 Using optical coherence tomography, thickness measurements of the entire retina, individual retinal layers and the choriocapillaris were acquired from $\mathrm{Cln}^{-/-}$and control mice

\begin{tabular}{|c|c|c|c|c|}
\hline Measurement & Group & Mean $(\mu \mathrm{m})$ & $P$ value & Standard error \\
\hline Whole retina & Control, $\mathrm{Cln} 8^{-/-}$ & 198,126 & $1.0 e^{-9 *}$ & 10.4 \\
\hline Retinal nerve fiber layer/ganglion cell layer & Control, $\mathrm{Cln}^{-/-}$ & 18,17 & 0.31 & 0.9 \\
\hline Inner plexiform layer & Control, $\mathrm{Cln}^{-/-}$ & 43,41 & 0.21 & 4.5 \\
\hline Inner nuclear layer & Control, $\mathrm{Cln}^{-/-}$ & 22,22 & 0.23 & 1.1 \\
\hline Outer nuclear layer & Control, $\mathrm{Cln}^{-/-}$ & 53,12 & $1.0 e^{-9 *}$ & 1.2 \\
\hline Combined inner and outer photoreceptor segments & Control, $\mathrm{Cln}^{-/-}$ & 46,19 & $1.0 e^{-9 *}$ & 0.8 \\
\hline Retinal pigmented epithelium & Control, $\mathrm{Cln}^{-/-}$ & 9,9 & 0.06 & 0.3 \\
\hline Choriocapillaris & Control, $\mathrm{Cln} 8^{-/-}$ & 5,5 & 0.23 & 0.2 \\
\hline
\end{tabular}

Measurements were taken at approximately $0.2 \mathrm{~mm}$ on either side of the optic nerve and averaged for each eye. $\mathrm{N}=3$ for each group. *, significant differences are demarcated.

collected from $C \ln 8^{-/-}$and control mice using OCT are represented in Table 1. Distinct inner and outer photoreceptor segments could not be distinguished in images from any eye of $\operatorname{Cln} 8^{-/-}$mice, whereas a clear IS/ OS junction (aka ellipsoid zone) distinction was notable between segments in images from control eyes. Whole retinal thickness in $\mathrm{Cln}^{-/-}$was significantly thinner than controls $\left(\mathrm{P}=1 \mathrm{e}^{-9}, \mathrm{SE}=10.4\right)$, with significant differences noted in outer nuclear layer $\left(\mathrm{P}=1 \mathrm{e}^{-9}, \mathrm{SE}=0.1 .2\right)$, and combined photoreceptor inner and outer segments $\left(\mathrm{P}=1 \mathrm{e}^{-9}\right.$, $\mathrm{SE}=0.8)$. There was no significant difference noted in retinal nerve fiber layer $(\mathrm{P}=0.3, \mathrm{SE}=0.9)$, inner plexiform layer $(\mathrm{P}=0.2, \mathrm{SE}=4.5)$, inner nuclear layer $(\mathrm{P}=0.2, \mathrm{SE}$ $=1.1)$, outer plexiform layer $(\mathrm{P}=0.2, \mathrm{SE}=0.6)$, or retinal pigmented epithelium $(\mathrm{P}=0.06, \mathrm{SE}=0.3)$ thickness between groups. Comparative OCT b-scans from $\operatorname{Cln} 8^{-/-}, C \ln 8^{+/-}$, and wildtype mice with a bar graph illustrating mean retinal layer measurements are represented in Figure 2.

\section{Electroretinography}

A globally reduced ERG waveform, with severely reduced a- and b-waves, was noted in all $\operatorname{Cln} 8^{-/-}$mice compared to those of wildtype and $C \ln 8^{+/-}$mice. Representative ERG waveforms from $\operatorname{Cln} 8^{-/-}, C \ln 8^{+/-}$, and wildtype mice are shown in Figure 3A-3C.

Quantitative comparisons of the stimulus-response curve illustrating mean a- and b-wave amplitudes are represented in Figure 3D,3E.

\section{Histopathology}

Retinal measurements and their associated $\mathrm{P}$ values collected from histologic sections of $\operatorname{Cln} 8^{-/-}$and control mice are presented in Table 2. Whole retinal thickness in $C \ln 8^{-/-}$was significantly thinner than controls $(\mathrm{P}=0.03$, $\mathrm{SE}=14.0$ ), with statistically significant thinning of the outer nuclear layer $(\mathrm{P}=0.01, \mathrm{SE}=2.3)$, and photoreceptor outer segments $(\mathrm{P}=0.001, \mathrm{SE}=2.8)$ in $\operatorname{Cln} 8^{-/-}$mice. Slight increases in thickness were noted in the inner plexiform layer $(\mathrm{P}=0.02, \mathrm{SE}=3.0)$ and inner nuclear layer $(\mathrm{P}=0.004$, $\mathrm{SE}=1.5)$ of $\operatorname{Cln} 8^{-/-}$mice. There was no significant difference noted in retinal nerve fiber layer $(\mathrm{P}=0.5 \mathrm{SE}=2.6)$, outer plexiform layer $(\mathrm{P}=0.1 \mathrm{SE}=0.8)$, photoreceptor inner segments $(\mathrm{P}=0.5, \mathrm{SE}=1.4)$, or retinal pigmented epithelium $(\mathrm{P}=0.17, \mathrm{SE}=0.3)$ thickness measurements between groups. Comparative values obtained from $\mathrm{H} \& \mathrm{E}$ sections from $\mathrm{Cln}^{\gamma^{-/}}$and control mice are represented in Figure 4.

To determine the retinal neurons most susceptible to cell death in the absence of $C \ln 8$, TUNEL labeling and cPARP immunohistochemistry were used to identify apoptotic cells. TUNEL labeling was found in the outer nuclear layers in $\mathrm{Cln}^{-/-}$mice but not in controls. Many rhodopsin positive rod photoreceptors were positive for cPARP in $\mathrm{Cln} 8^{-/-}$ mice, but not in controls (Figure 5). These findings suggest rod photoreceptors are the most vulnerable in the absence 


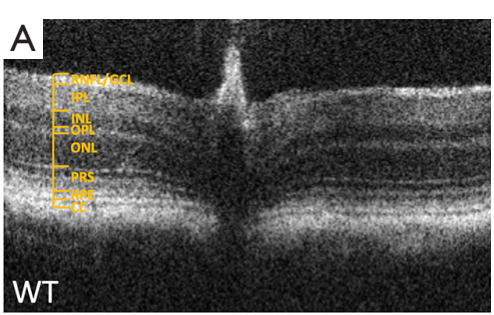

D

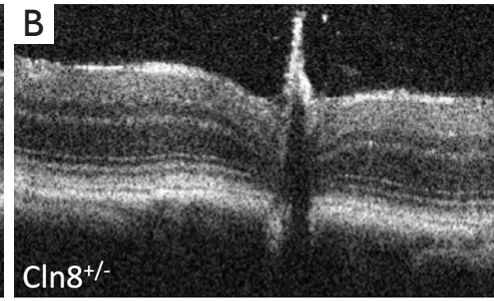

Retinal thickness $(\mu \mathrm{m})$
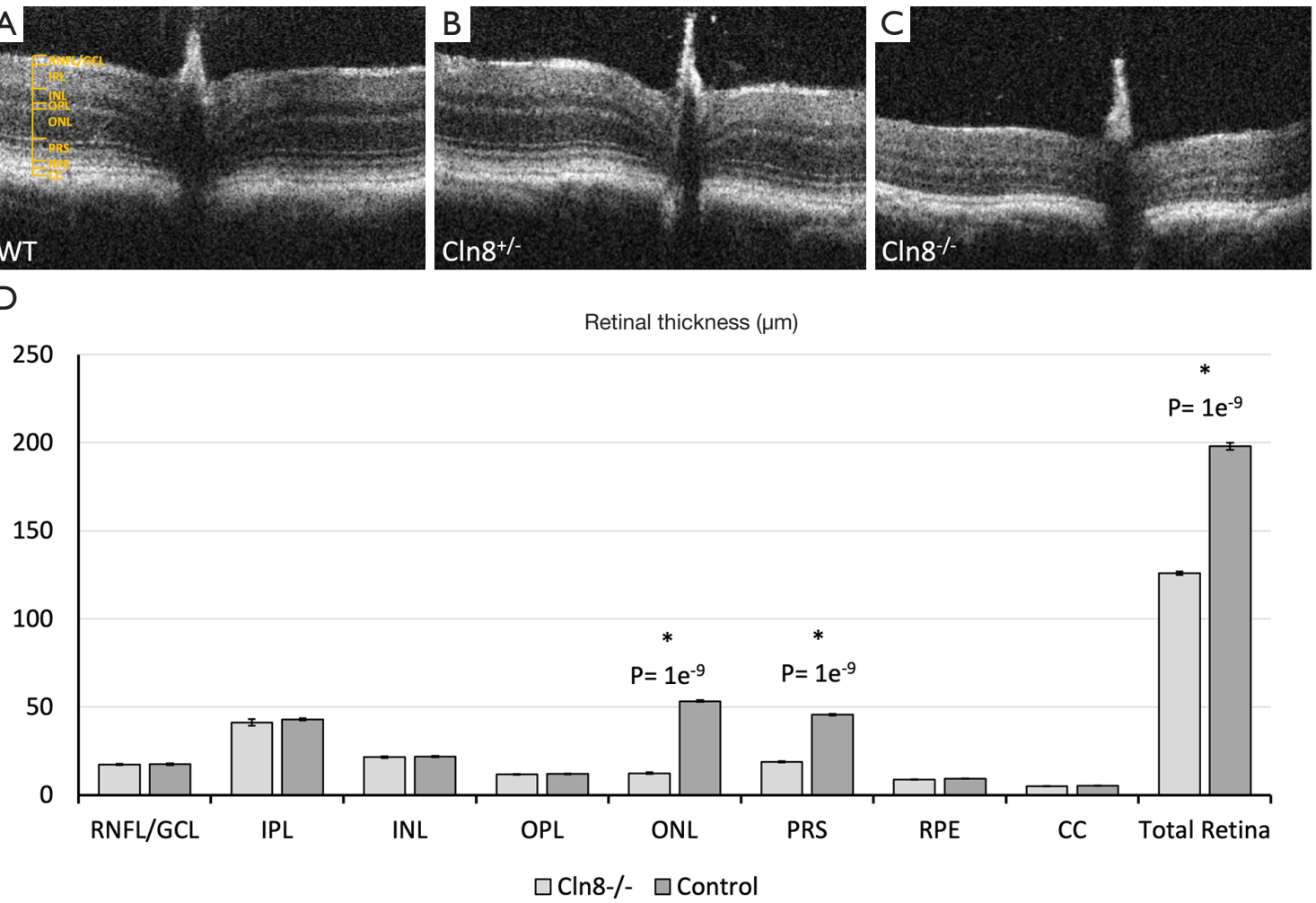

Figure 2 Comparison of OCT between wildtype, $C \ln 8^{+/-}$, and $C \ln 8^{-/-}$mice. (A) Retinal architecture in a wildtype $\mathrm{C} 57 \mathrm{BL} / 6 \mathrm{~N} r d 8$ mouse, and (B) in a $\mathrm{Cln}^{+/-}$mouse. (C) OCT of a $\mathrm{Cln}^{-/-}$mouse retina demonstrating marked outer nuclear layer thinning, a loss of definition in the inner and outer segments of the photoreceptors, and diffuse retinal thinning. (D) Bar graph showing mean retinal layer thickness measurements in $C \ln 8^{-/-}$and control mice on OCT images. *, statistical significance, $\mathrm{P}<0.05$ two-tailed student's $t$-test. RNFL/GCL, retinal nerve fiber layer/ganglion cell layer; IPL, inner plexiform layer; INL, inner nuclear layer; OPL, outer plexiform layer; ONL, outer nuclear layer; PRS, photoreceptor segments; RPE, retinal pigmented epithelium; CC, choriocapillaris.

of $\mathrm{C} \ln 8$ and undergo profound apoptosis. Furthermore, their outer segments, marked by rhodopsin, are shortened, suggesting a role for $\mathrm{C} \ln 8$ in outer segment elaboration and morphology.

\section{Necropsy}

All organ systems were unremarkable on gross examination in $C \ln 8^{-/-}$mice, however on histologic examination scattered lipid vacuoles were noted in splenic red pulp of all knockout mice. Observations in control mice was limited to identifying an enlarged heart in $1 / 3$ control mice.

\section{Clinical correlation}

The abnormalities seen on retinal imaging of $\mathrm{Cln}^{-/-}$mice were compared with humans with confirmed CLN8- asociated retinopathy. We include follow up clinical evaluation and fundus features of the individuals described by Sanchez et al. (10).

Case 1 is a now 20-year-old Hispanic female who presented with decreased central vision at around age 13 years and well controlled generalized tonic clonic seizures (GTC) since age 7 years of age as reported by Sanchez et al. (10). She has a diagnosis of CLN8 based on a likely pathogenic deletion encompassing the entire CLN8 gene and a c.200C > T (p.A67V) variant of unknown significance on this gene confirmed in trans, and electron microscopy of lymphocytes showing intracytoplasmic inclusions. She was noted to have cystoid macular edema (CME) bilaterally, with visual acuity of 20/40 OU at time of initial report and more recently OD $20 / 80+2$ and OS 20/100. On follow up ophthalmologic evaluation she had attenuated vasculature with cystoid macular edema and diffuse retinal pigment epithelium 


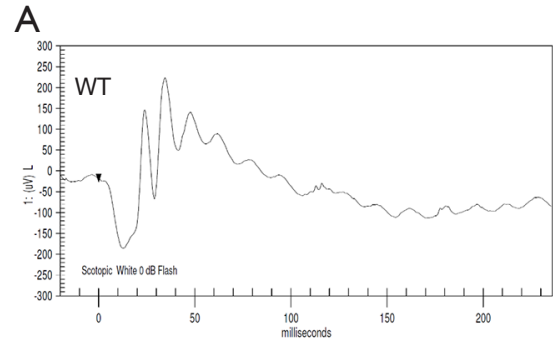

D

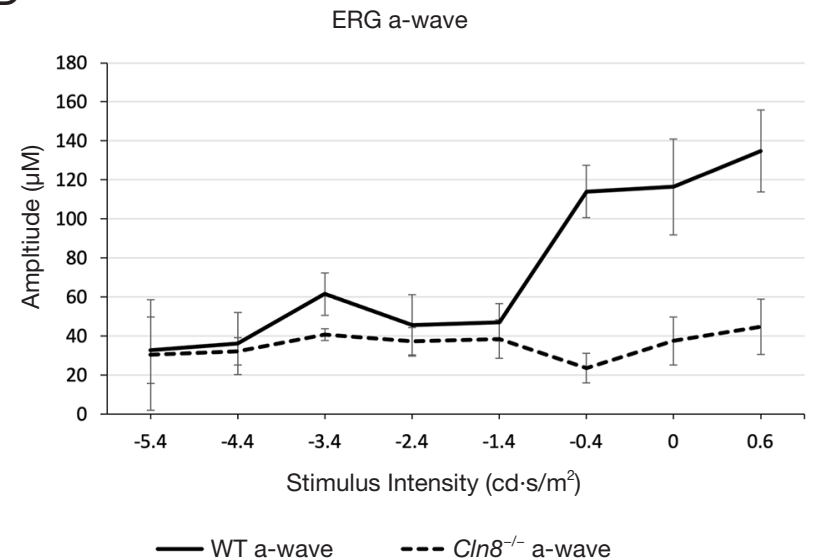

B

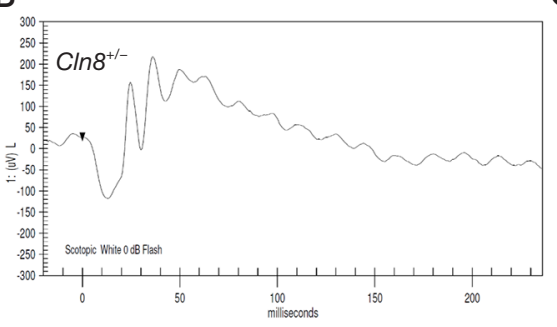

E

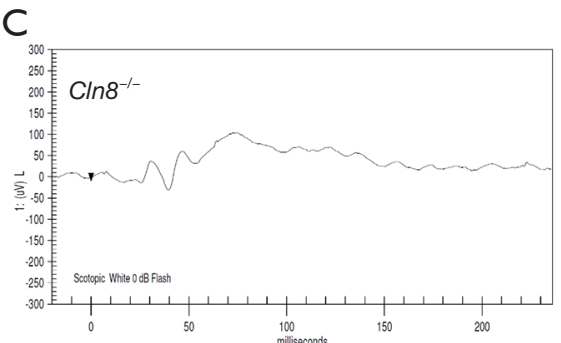

ERG b-wave

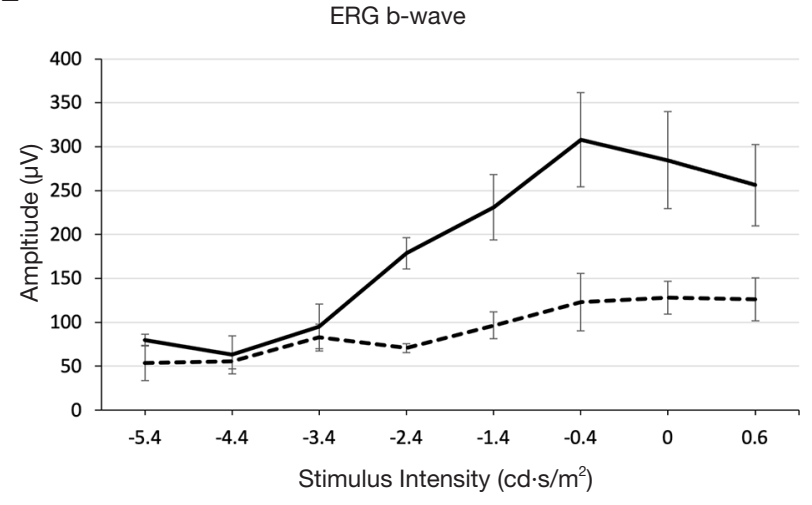

-WT b-wave $\quad---\mathrm{C} / n 8^{-/-}$b-wave

Figure 3 Comparison of electroretinography tracings in wildtype, $C \ln 8^{+/-}$, and $C \ln 8^{-/}$mice. With scotopic bright flash $(0 \mathrm{~dB})$, normal tracings are present in a (A) wildtype $\mathrm{C} 57 \mathrm{BL} / 6 \mathrm{~N} r d 8$ mouse and (B) $C \ln 8^{+/-}$mouse, with reduced a- and b-wave amplitudes in a $C \ln 8^{-/-}$mouse (C). Line graphs denote mean a-wave (D), and b-wave (E) amplitudes at varying stimulus intensities in $C \ln 8^{-/-}(\mathrm{n}=3)$ and wildtype $(\mathrm{n}=4)$ mice; note the severely reduced a- and b- wave amplitudes in $C \ln 8^{-/-}$(dashed lines) compared to wildtype (solid lines) mice. Error bars represent SEM.

Table 2 Histology measurements collected from $\operatorname{Cln} 8^{-/-}(\mathrm{n}=3)$ and control $(\mathrm{n}=3)$ mice

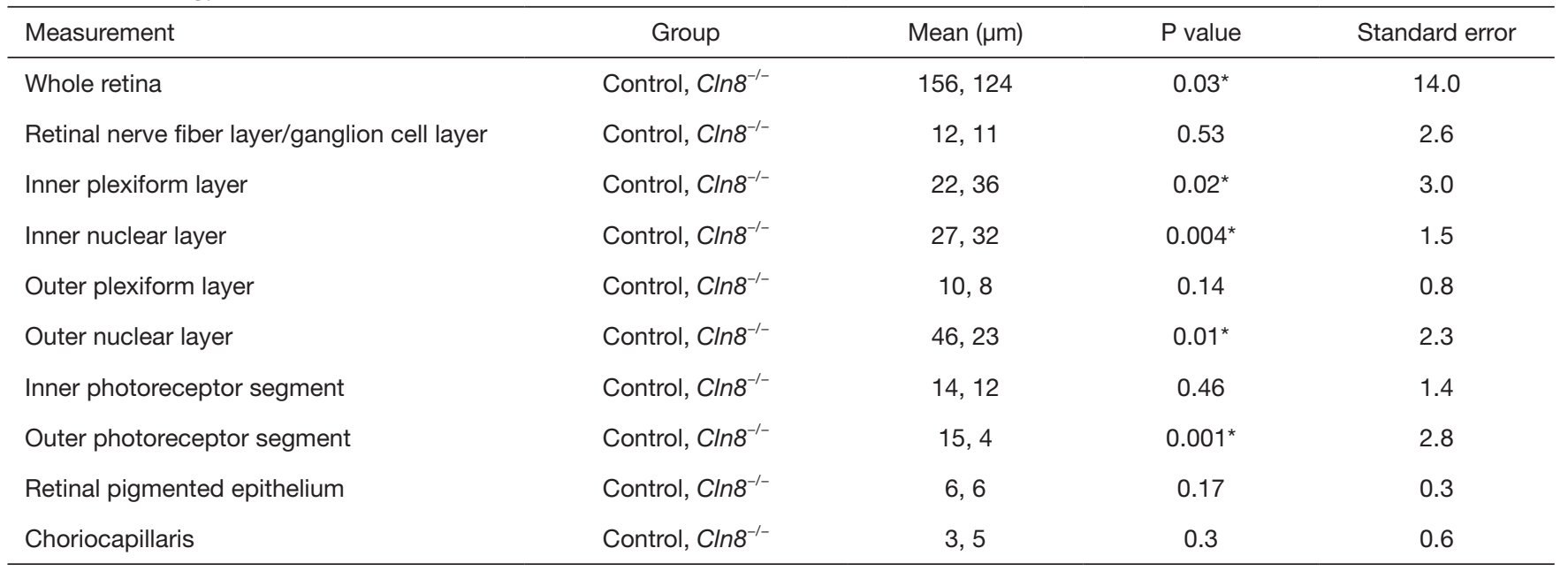

Histologic sections were chosen at the level of the optic nerve and measurements were taken approximately adjacent to the optic nerve head in the posterior retina. *, statistical significance, $\mathrm{P}<0.05$ student's $t$-test. 


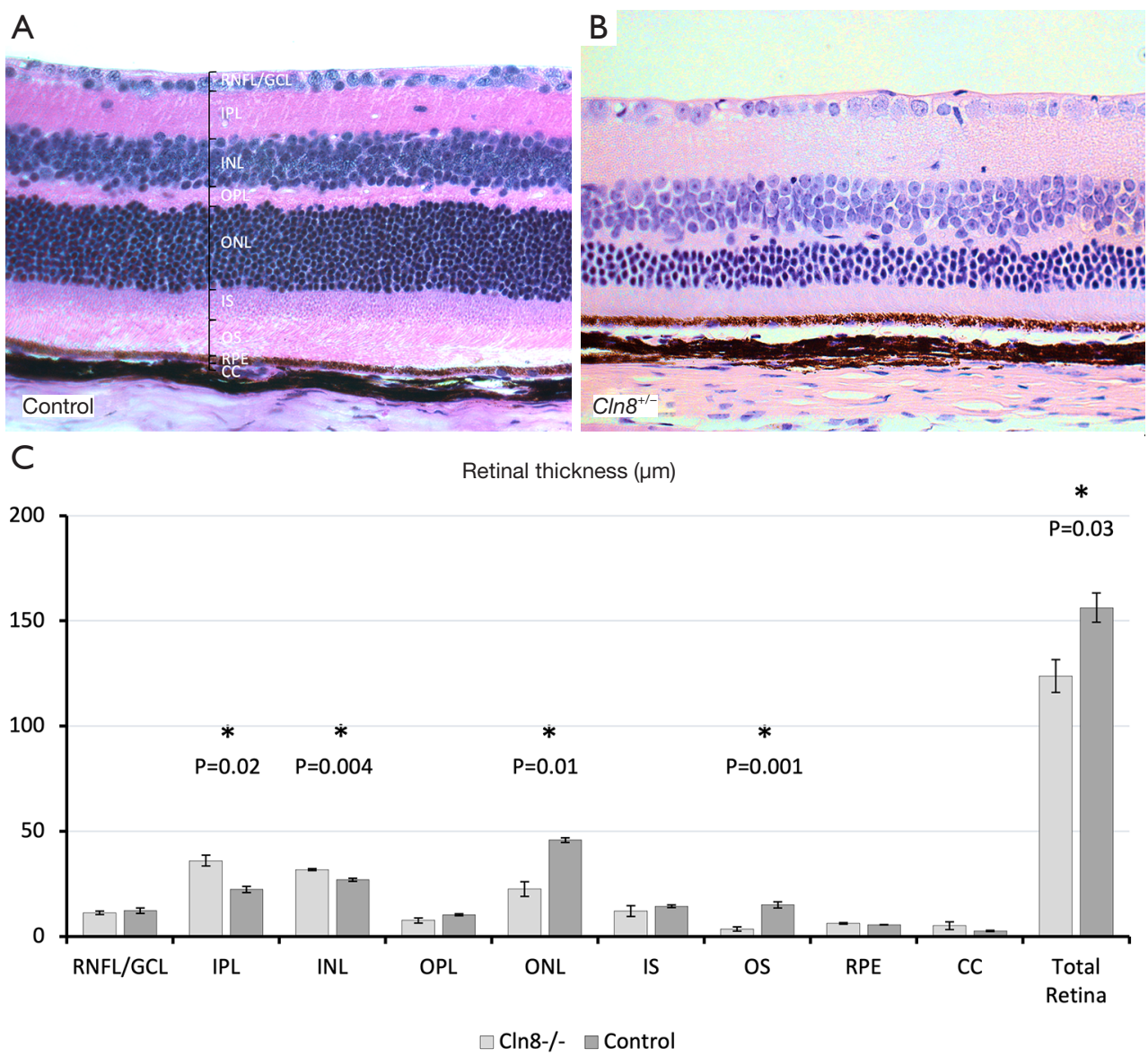

Figure 4 Comparison of histologic retinal sections between $C \ln 8^{-/-}$and control mice. (A) Retinal architecture in control C57BL/6N $r d 8$ mouse. (B) H\&E of a $C \ln 8^{-/-}$mouse retina demonstrating mild thickening of the inner plexiform and inner nuclear layer, with marked outer nuclear layer thinning and whole retinal thinning. (C) Bar graph showing mean retinal layer thickness measurements in histologic sections of $C \ln 8^{-/-}(\mathrm{n}=3)$ and control $(\mathrm{n}=4)$ mice. *, statistical significance, $\mathrm{P}<0.05$ two-tailed student's $t$-test). Histology images taken at $\times 40$. RNFL/GCL, retinal nerve fiber layer/ganglion cell layer; IPL, inner plexiform layer; INL, inner nuclear layer; OPL, outer plexiform layer; ONL, outer nuclear layer; IS, inner photoreceptor segment; OS, outer photoreceptor segment; RPE, retinal pigmented epithelium; CC, choriocapillaris.

mottling (Figure 6) as well as trace posterior subcapsular cataract (PSC). Spectral domain OCT had demonstrated macular cystic change and diffuse macular schisis involving the outer nuclear and the outer plexiform layers. In the past year, OCT showed the retinal CME persists but has had mild improvement. Goldmann visual field (GVF) revealed large central scotomas bilaterally which have been stable on follow up. She has had one breakthrough seizure described as GTC after original report that lasted 5 minutes and post-ictal state of 10 minutes with sleepiness. She has been well controlled with Keppra since this episode. No repeat brain imaging has been done. Following the original report, she had formal psychological evaluation showing anxiety and depression but normal cognitive function.

She has had a prior diagnosis of ADHD but is currently not treated for this.

Case 2 is now a 28 -year-old Hispanic male sibling of Case 1, with history of decrease in night vision starting at age 5 years old and seizures starting at age 16 years as previously reported. Molecular testing revealed the same variants as his affected sibling on the CLN8 gene. At age 22 years his visual acuity was OD 20/25 and OS 20/30 which remained unchanged at age 28 years. Fundus exam originally revealed pallor of optic nerves, attenuated 

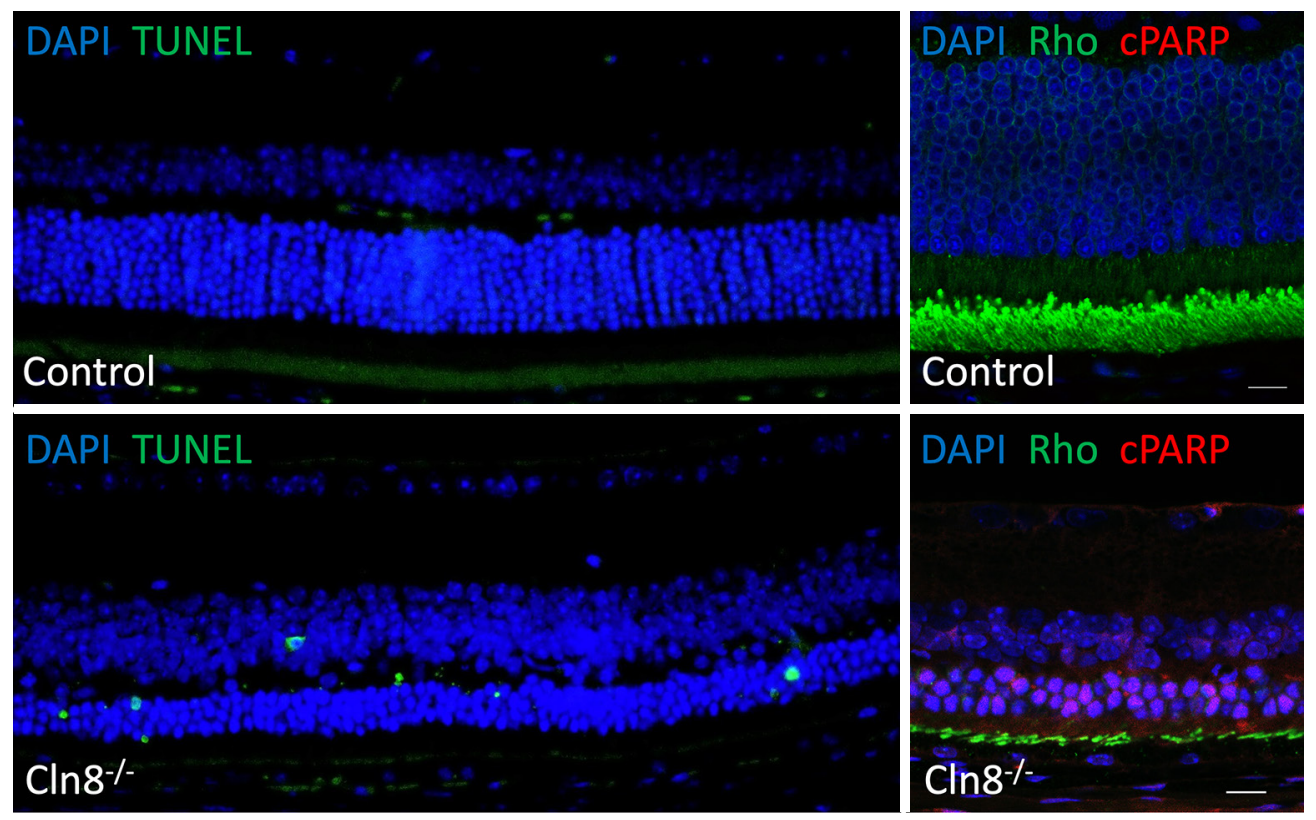

Figure 5 Photoreceptors undergo apoptosis in the absence of Cln8. Control retinal sections (top row) show no TUNEL-positive nuclei and no cPARP-positive cells in the rhodopsin labeled outer nuclear layer. $C \ln 8^{-/-}$mice (bottom row) have numerous TUNEL-positive cells in the outer nuclear layer. Many rhodopsin-positive rod photoreceptors are also cPARP-positive in Cln8 knockouts. Furthermore, rhodopsin positive outer segments are much shorter in $C \ln 8^{-/-}$mice than controls. Scale bar in right column represents 10 microns.
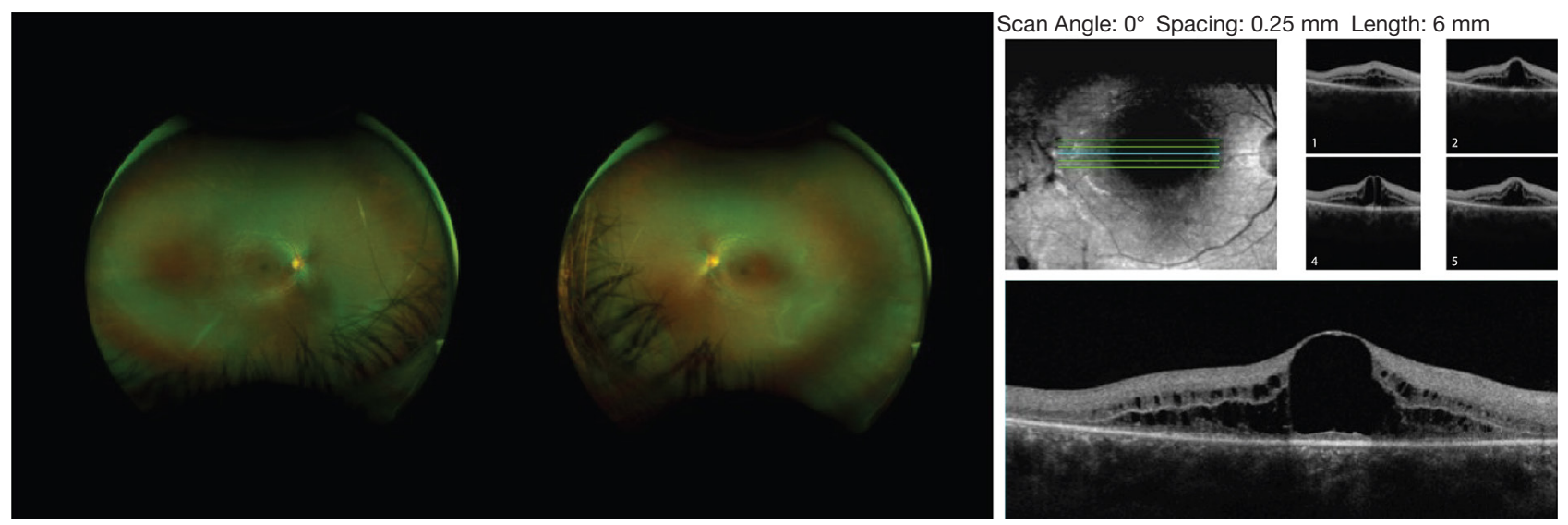

Figure 6 Bilateral fundus images showing attenuated vasculature and diffuse retinal pigment epithelium mottling. OCT of the right eye showing cystoid macular edema.

vasculature, peripheral bone spicules and diffuse retinal pigment epithelial mottling. On recent follow up, fundus examination and ultrawide field color fundus imaging showed mid-peripheral bone spicules and mild attenuation of vasculature (Figure 7). OCT showed no CME and fundus autofluorescence showed scattered macular areas of decreased and increased intensity. Since the initial report he has had one witnessed generalized tonic clonic seizure lasting less than one minute in the setting of weaning of his anti-epileptic medication which has since been adjusted.

He has not had any recent brain imaging and has not had a formal psychoeducational evaluation, but he has a master's degree in engineering and continues to work full-time job 


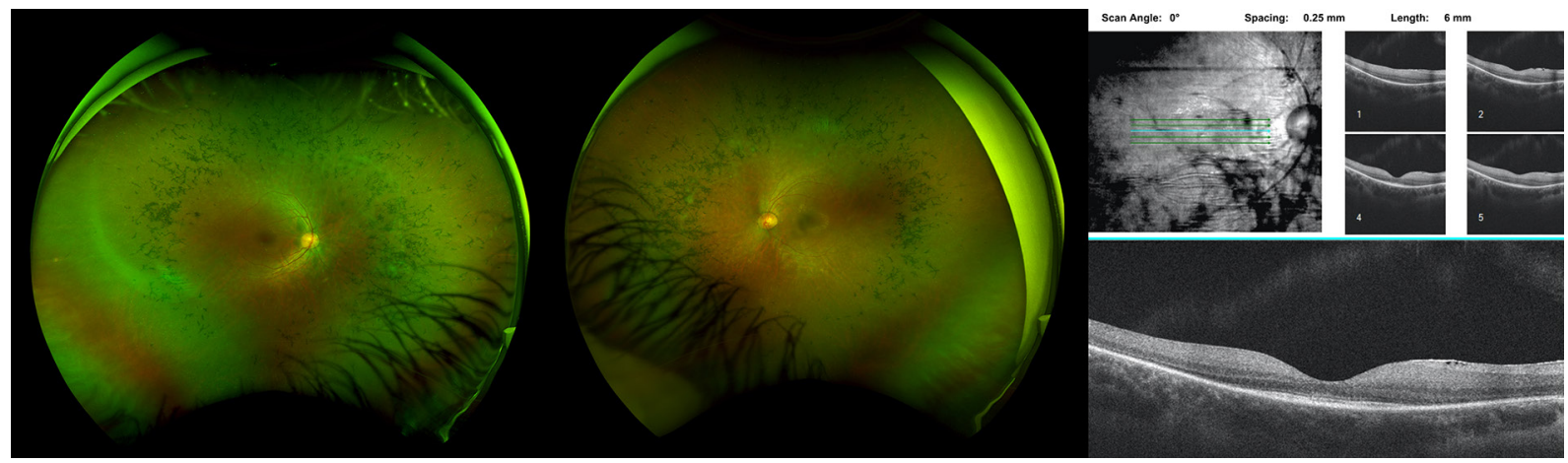

Figure 7 Fundus images showing pallor of optic nerves, attenuated vasculature, mid-peripheral bone spicules and diffuse retinal pigment epithelial mottling. The nasal and temporal sides of the macular OCT show outer retinal thinning and loss of the IS/OS junction similar to that seen in mice

living independently.

\section{Discussion}

This study details the phenotypic attributes of retinal degeneration in $\mathrm{Cln}^{8^{-/-}}$mice using several testing modalities at 16 weeks postnatal age, providing a promising murine model for CLN8 ophthalmic disease in humans.

The single previous report with indirect ophthalmoscopic findings in mnd mice reports similar retinal pathology to that noted in this study: severe retinal vessel attenuation, focal and diffuse loss of pigment epithelium, and patches of pigment deposits (33). These lesions were not appreciable until approximately 5 months of age in the aforementioned study, while similar abnormalities were detected in this study by 4 months of age. This variation in timeline may be due to differences between the spontaneous mutation in mnd mice and the targeted $C \ln 8$ deletion in this study, or due to strain-specific background differences. Chang et al. used backcrossing of mice with a spontaneously occurring Cln 8 mutation (33), while the current study employed engineered $C \ln 8$ gene knockout. Moreover, genetic background has been shown to affect the age of onset, speed of progression, precise neurological symptoms and type of cells affected in mnd mice (46). The aforementioned study used outcrossed C57BL/6J $\times$ AKR/J mice. A slightly more rapid retinal degeneration may be secondary to the $\mathrm{rd} 8$ mutation present in the $\mathrm{C} 57 \mathrm{BL} / 6 \mathrm{~N}$ mice used in the current study, though it is difficult to definitively determine the secondary effect of the background strain, as the C57BL/6J strain wildtype mice also possess the $\mathrm{rd} 8$ mutation without displaying the phenotype (44). Published electroretinography abnormalities in $m n d$ mice closely resemble those found in this study, with barely detectable waveforms only with the brightest stimulus by 5 months of age, and undetectable waveforms with single-flash methods at 6 months of age (33).

Previous histologic evaluation of retinal changes in mnd mice noted reduced numbers of photoreceptors and significant reduction in outer nuclear layer thickness, with one study noting the onset of these changes at 5 weeks of age (33), while another study documented photoreceptor layer atrophy in mice older than 3 months of age (40).

These changes are consistent with the reduced outer nuclear layer and photoreceptor segment thinning appreciated on OCT and histology in this study. Another study found that a prominent feature of photoreceptor degeneration in mnd mice was the persistent and progressive shortening of photoreceptor outer segments, while shortening of inner segments was less pronounced and occurred at a much later stage of degeneration (35). The histologic findings in the current study support this finding, in which significant thinning was noted in outer but not inner photoreceptor segments of $\mathrm{Cln}^{-/-}$mice.

While this study and previous reports $(33,40)$ noted significant thinning of the outer retina in CLN8 murine models, Groh et al. (17) described predominant thinning of the inner retina in CLN1 and CLN3 murine models. Significant thinning of the nerve fiber layer, ganglion cell layer, inner plexiform layer, and inner nuclear layer was appreciated in 7-month-old CLN1 mice and 16 month old CLN3 mice (17). Although this variation in retinal layer predilection may reflect differences in pathophysiology amongst CNL diseases, it is interesting to note that PAS 
staining inclusions have been noted in retinal ganglion cells of mnd mice $(33,34)$. Ultrastructural examination of the retina was not available in the current study and was thus unable to investigate intracellular changes such as inclusions. Further studies are warranted to evaluate intracellular changes in CLN8 retinal layers.

Variation in phenotypic presentation of retinopathy has been noted in humans with mutations in CLN8, with main ocular lesions ranging from cystoid macular edema, diffuse macular schisis, optic disk atrophy, peripheral bone spicules, and retinal atrophy $(10,47,48)$. Significant similarities are noted between the limited descriptive reports available of retinopathy in humans with CLN8 and $\operatorname{Cn} \ln 8^{-/-}$mice of this study, including attenuated retinal vasculature and diffuse retinal pigment epithelial mottling (10).

Additionally, attenuated rod and cone photoreceptor function was noted in numerous reports of CLN8 in humans, similar to that noted in the current study (10,47-49).

No gross abnormalities were noted in the brain or other extraocular organs in $\operatorname{Cln} 8^{-/-}$mice on necropsy in this study, though scattered lipid vacuoles were noted in splenic red pulp of all $\operatorname{Cn} 8^{-/-}$mice. This contrasts with reports of nonophthalmic cellular pathology in mnd mice, encompassing cytoplasmic inclusion material in liver, heart, smooth and skeletal muscle, lamina propria of the intestine, pancreatic ducts, uterine glands, endothelial cells in the skin, and renal tubular epithelial cells (40). This difference in affected organs may be due to different levels of tissue evaluation, as ultrastructural analysis in the current study may have identified inclusions in organs lacking gross histologic abnormalities. In addition, specialized systems within each organ were not individually analyzed, such as the retinotectal system, which may have improved our ability to detect subtle lesions. None of the $\operatorname{Cln} 8^{-/-}$mice displayed obvious CNS (Central Nervous System) abnormalities however, such as premature death or seizures, which may support the absence of lesions noted in CNS organs on necropsy and histopathology in the current study. Non-ophthalmic abnormalities well documented in humans include cerebral and cerebellar atrophy, as well as white matter changes (47-50). Further studies are warranted to investigate gross CNS pathology in murine models of CLN8.

Limitations of the current study include a small study population and the cross-sectional nature of data collection at a single time point. Although a small study population may have resulted in discordant inner nuclear and inner plexiform layer measurements between groups in OCT and $\mathrm{H} \& \mathrm{E}$ images, the difference in layer thickness between these modalities is small and could be related to tissue fixation and processing. Significant thinning of the outer nuclear layer, outer photoreceptor segments, and whole retina in mice with $\mathrm{Cln} 8^{-/-}$were detected with confidence.

Additionally, a clear clinical and electrophysiologic phenotype could be described with the small number of study animals.

Despite minor limitations of this study, the overall similarities of ocular pathology in $\operatorname{Cnn} 8^{-/-}$mice with the human disease suggests strong potential as a murine model for testing therapies in preclinical models. Future longitudinal studies with a larger study population are warranted to determine developmental onset and possible progression of retinal degeneration. Such studies would inform ideal ages for assessment of therapeutic strategies aimed at preventing or mitigating the visual consequences in this murine model that would be most translatable to the treatment of the human disease.

\section{Conclusions}

In conclusion, $\operatorname{Cln} 8^{-/-}$mice provide a potential alternative murine model for retinopathy in patients with CLN8 due to similar anatomic and electrophysiologic retinal pathology. This animal model may serve as a tool for therapeutic development and disease management.

\section{Acknowledgments}

The authors wish to acknowledge and thank Monica Motta and Brad Shibata for outstanding technical support and the NEI Microscopy Core (P30EY12576) led by Dr. Paul FitzGerald. The authors also thank Brandon Willis for his contributions in the genetic construct design and all the MBP staff for their assistance. The authors thank the International Mouse Phenotyping Consortium.

Funding: The study was supported by NIH funding source of the KOMP (UM1OD023321). SPS receives grant support from Children's Miracle Endowed Chair in Pediatric Genetics.

\section{Footnote}

Provenance and Peer Review: This article was commissioned by the Guest Editor (Susanna S. Park) for the series "Novel Tools and Therapies for Ocular Regeneration" published in Annals of Translational Medicine. The article has undergone external peer review. 
Reporting Checklist: The authors have completed the ARRIVE reporting checklist. Available at https://dx.doi. org/10.21037/atm-20-4739

Data Sharing Statement: Available at https://dx.doi. org/10.21037/atm-20-4739

Conflicts of Interest: All authors have completed the ICMJE uniform disclosure form (available at https://dx.doi. org/10.21037/atm-20-4739). The series "Novel Tools and Therapies for Ocular Regeneration" was commissioned by the editorial office without any funding or sponsorship. Dr. CJM reports grants from NIH, during the conduct of the study. Dr. AM reports grants from NIH National Eye Institute (K08EY027463), during the conduct of the study. The authors have no other conflicts of interest to declare.

Ethical Statement: The authors are accountable for all aspects of the work in ensuring that questions related to the accuracy or integrity of any part of the work are appropriately investigated and resolved. The study was conducted in accordance with the Declaration of Helsinki (as revised in 2013). The study was approved by the Institutional Review Board of Emory University (No. MODCR001-IRB00024817) and informed consent was taken from both patients. Experiments were performed under a project license (No. IACUC \# 21824) granted by the Institutional Animal Care and Use Committee at UC Davis, in compliance with the National Institutes of Health (NIH) Guide for the Care and Use of Laboratory Animals and the guidelines of the Association for Research in Vision and Ophthalmology Statement for the Use of Animals in Ophthalmic and Vision Research.

Open Access Statement: This is an Open Access article distributed in accordance with the Creative Commons Attribution-NonCommercial-NoDerivs 4.0 International License (CC BY-NC-ND 4.0), which permits the noncommercial replication and distribution of the article with the strict proviso that no changes or edits are made and the original work is properly cited (including links to both the formal publication through the relevant DOI and the license). See: https://creativecommons.org/licenses/by-nc-nd/4.0/.

\section{References}

1. Brown SD, Moore MW. Towards an encyclopaedia of mammalian gene function: the International Mouse
Phenotyping Consortium. Dis Model Mech 2012;5:289-92.

2. Brown SD, Moore MW. The International Mouse Phenotyping Consortium: past and future perspectives on mouse phenotyping. Mamm Genome 2012;23:632-40.

3. Mole SE, Williams RE, Goebel HH. The Neuronal Ceroid Lipofuscinoses (Batten Disease). 2ed. Oxford: UKL Oxford University Press, 2011.

4. Herva R, Tynela J, Hirvasniemi A, et al. Northern epilepsy: a novel form of neuronal ceroid lipofuscinosis. Brain Pathol 2000;10:215-22.

5. Ranta S, Lehesjoki AE. Northern epilepsy, a new member of the NCL family. Neurol Sci 2000;21:S43-7.

6. di Ronza A, Bajaj L, Sharma J, et al. CLN8 is an ER cargo receptor that regulates lysosome biogenesis. Nat Cell Biol 2018;20:1370-7.

7. Quagliato EMAB, Rocha DM, Sacai PY, et al. Retinal function in patients with the neuronal ceroid lipofuscinosis phenotype. Arq Bras Oftalmol 2017;80:215-9.

8. Pagon RA, Adam MP, Ardinger HH, et al. editor. GeneReviews. Seattle (WA): University of Washington, Seattle, 2001.

9. Williams RE, Aberg L, Autti T, et al. Diagnosis of the neuronal ceroid lipofuscinoses: an update. Biochim Biophys Acta 2006;1762:865-72.

10. Sanchez RL, Yan J, Richards S, et al. Atypical presentation of neuronal ceroid lipofuscinosis type 8 in a sibling pair and review of the eye findings and neurological features. Am J Ophthalmol Case Rep 2016;4:50-3.

11. Kohlschütter A, Schulz A, Bartsch U, et al. Current and emerging treatment strategies for Neuronal Ceroid Lipofuscinoses. CNS Drugs 2019;33:315-25.

12. Markham A. Cerliponase alfa: first global approval. Drugs 2017;77:1247-9.

13. Schulz A, Ajayi T, Specchio N, et al. Study of intraventricular cerliponase alfa for CLN2 disease. N Engl J Med 2018;378:1898-907.

14. Ahtiainen L, Luiro K, Kauppi M, et al. Palmitoyl protein thioesterase 1 (PPT1) deficiency causes endocytic defects connected to abnormal saposin processing. Exp Cell Res 2006;312:1540-53.

15. Gupta P, Soyombo AA, Atashband KE, et al. Disruption of PPT1 or PPT2 causes neuronal ceroid lipofuscinosis in knockout mice. Proc Natl Acad Sci USA 2001;98:13566-71.

16. Jalanko A, Vesa J, Manninen T, et al. Mice with Ppt1Deltaex 4 mutation replicate the INCL phenotype and show an inflammation-associated loss of interneurons. Neurobiol Dis 2005;18:226-41. 
17. Groh J, Stadler D, Buttman M, et al. Non-invasive assessment of retinal alterations in mouse models of infantile and juvenile neuronal ceroid lipofuscinosis by spectral domain optical coherence tomography. Acta Neuropathol Commun 2014;2:54.

18. Sleat DE, El-Banna M, Sohar I, et al. Residual levels of tripeptidyl-peptidase I activity dramatically ameliorate disease in late-infantile neuronal ceroid lipofuscinosis. Mol Genet Metab 2008;94:222-33.

19. Cotman SL, Vrbanac V, Lebel LA, et al. Cln3(Deltaex7/8) knock-in mice with the common JNCL mutation exhibit progressive neurologic disease that begins before birth. Hum Mol Genet 2002;11:2709-21.

20. Ding SL, Tecedor L, Stein CS, et al. A knock-in reporter mouse model for Batten disease reveals predominant expression of $\mathrm{Cln} 3$ in visual, limbic and subcortical motor structures. Neurobiol Dis 2011;41:237-48.

21. Eliason SL, Stein CS, Mao Q, et al. A knock-in reporter model of Batten disease. J Neurosci 2007;27:9826-34.

22. Finn R, Kovacs AD, Pearce DA. Altered sensitivity of cerebellar granule cells to glutamate receptor overactivation in the $\mathrm{Cln} 3$ (Deltaex7/8)-knockin mouse model of juvenile neuronal ceroid lipofuscinosis. Neurochem Int 2011;58:648-55.

23. Greene ND, Bernard DL, Taschner PE, et al. A murine model for juvenile NCL: gene targeting of mouse $\mathrm{Cln} 3$. Mol Genet Metab 1999;66:309-13.

24. Katz ML, Johnson GS, Tullis GE, et al. Phenotypic characterization of a mouse model of juvenile neuronal ceroid lipofuscinosis. Neurobiol Dis 2008;29:242-53.

25. Katz ML, Shibuya H, Liu PC, et al. A mouse gene knockout model for juvenile ceroid-lipofuscinosis (Batten disease). J Neurosci Res 1999;57:551-6.

26. Mitchison HM, Bernard DJ, Greene ND, et al. Targeted disruption of the $\mathrm{Cln} 3$ gene provides a mouse model for Batten disease. The Batten Mouse Model Consortium. Neurobiol Dis 1999;6:321-34.

27. Osório NS, Sampaio-Marques B, Chan CH, et al. Neurodevelopmental delay in the Cln3Deltaex7/8 mouse model for Batten disease. Genes Brain Behav 2009;8:337-45.

28. Seigel GM, Lotery A, Kummer A, et al. Retinal pathology and function in a $\operatorname{cln} 3$ - knockout mouse model of juvenile ceroid lipofuscinosis (Batten Disease). Mol Cell Neurosci 2002;19:515-27.

29. Kopra O, Vesa J, von Schantz C, et al. A mouse model for Finnish variant late infantile neuronal ceroid lipofuscinosis CLN5, reveals neuropathology associated with early aging.
Hum Mol Genet 2004;13:2893-906.

30. Gao H, Boustany RM, Espinola JA, et al. Mutations in a novel CLN6-encoded transmembrane protein cause variant neuronal ceroid lipofuscinosis in man and mouse. Am J Hum Genet 2002;70:324-35.

31. Faust JR, Rodman JS, Daniel PF, et al. Two related proteolipids and dolichol-linked oligosaccharides accumulate in motor neuron degeneration mice (mnd/ mnd), a model for neuronal ceroid lipofuscinosis. J Biol Chem 1994;269:10150-5.

32. Ranta S, Zhang Y, Ross B, et al. The neuronal ceroid lipofuscinoses in human EPMR and mnd mutant mice are associated with mutations in CLN8. Nat Genet 1999;23:233-6.

33. Chang B, Bronson RT, Hawes NL, et al. Retinal degeneration in motor neuron degeneration: a mouse model of ceroid lipofuscinosis. Invest Ophthalmol Vis Sci 1994;35:1071-6.

34. Seigel GM, Wagner J, Wronska A, et al. Progression of early postnatal retinal pathology in a mouse model of neuronal ceroid lipofuscinosis. Eye 2005;19:1306-12.

35. Messer A, Plummer J, Wong V, et al. Retinal degeneration in motor neuron degeneration (mnd) mouse. Exp Eye Res 1993;57:637-41.

36. Koike M, Shibata M, Waguri S, et al. Participation of autophagy in storage of lysosomes in neurons from mouse models of neuronal ceroid-lipofuscinoses (Batten disease). Am J Pathol 2005;167:1713-28.

37. Koike M, Nakanishi H, Saftig P, et al. Cathepsin, D deficiency induces lysosomal storage with ceroid lipofuscin in mouse CNS neurons. J Neurosci 2000;20:6898-906.

38. Leinonen H, Keksa-Goldstein V, Ragauskas S, et al. Retinal degeneration in a mouse model of CLN5 Disease is associated with compromised autophagy. Sci Rep 2017;7:1597.

39. Bronson RT, Donahue LR, Johnson KR, et al. Neuronal ceroid lipofuscinosis (nclf), a new disorder of the mouse linked to chromosome 9. Am J Med Genet 1998;77:289-97.

40. Bronson RT, Lake BD, FRC Path, et al. Motor neuron degeneration of mice is a model of neuronal ceroid lipofuscinosis (Batten's Disease). Ann Neurol 1993;33:381-5.

41. Guo J, Johnson GS, Brown HA, et al. A CLN8 nonsense mutation in the whole genome sequence of a mixed breed dog with neuronal ceroid lipofuscinosis and Australian Shepherd ancestry. Mol Genet Metab 2014;112:302-9.

42. Lingaas F, Guttersrud O-A, Arnet E, et al. Neuronal ceroid lipofuscinosis in Salukis is caused by a single base 
pair insertion in CLN8. Anim Genet 2018;49:52-8.

43. Guo J, Johnson GS, Cook J, et al. Neuronal ceroid lipofuscinosis in a German Shorthaired Pointer associated with a previously reported CLN8 nonsense variant. Mol Genet Metab Rep 2019;21:100521.

44. Moore BA, Roux MJ, Sebbag L, et al. A population study of common ocular abnormalities in C57BL/6N rd8 mice. Invest Ophthalmol Vis Sci 2018;59:2252-61.

45. Abramoff MD, Magalhaes PJ, Ram SJ. Image Processing with ImageJ. Biophotonics Int 2004;11:36-42.

46. Messer A, Plummer J, Macmillen MC, et al. Genetics of primary and timing effects in the mnd mouse. Am J Med Genet 1995;57:361-4.

Cite this article as: Salpeter EM, Leonard BC, Lopez AJ, Murphy CJ, Thomasy S, Imai DM, Grimsrud K, Lloyd KCK, Yan J, Sanchez Russo R, Shankar SP, Moshiri A. Retinal degeneration in mice and humans with neuronal ceroid lipofuscinosis type 8. Ann Transl Med 2021;9(15):1274. doi: 10.21037/atm-20-4739
47. Mahajnah M, Zelnik N. Phenotypic heterogeneity in consanguineous patients with a common CLN8 mutation. Pediatr Neurol 2012;47:303-5.

48. Allen NM, O'hlci B, Anderson G, et al. Variant late infantile neuronal ceroid lipofuscinosis due to a novel heterozygous CLN8 mutation and de novo 8p23.3 deletion. Clin Genet 2012;81:602-4.

49. Striano P, Specchio N, Biancheri R, et al. Clinical and electrophysiological features of epilepsy in Italian patients with CLN8 mutations. Epilepsy Behav 2007;10:187-91.

50. Jadav RH, Sinha S, Yasha TC, et al. Magnetic resonance imaging in neuronal ceroid lipofuscinosis and its subtypes. Neuroradiol J 2012;25:755-61. 